\title{
Modifiye lapidus prosedürünün uzun dönem sonuçları
}

\section{Long term results of modified lapidus procedure}

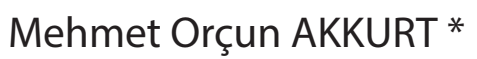

Ankara Yıldırım Beyazıt Üniversitesi, Yenimahalle Eğitim ve Araştırma Hastanesi, Ortopedi ve Travmatoloji Kliniği, Ankara/TURKEY

\section{Öz}

Amaç: Çalışmamızda 2004-2012 yılları arasında Modifye Lapidus prosedürü uyguladığımız 67 hastayı restrospektif olarak değerlendirdik.

Gereç ve Yöntemler: Hastaların 61'I Kadın,6'sı erkekti. Hastaların ortalama yaşı 51'di .Hastaların ortalama takip süresi yaklaşık 10yıl'dı (6-14 yıl). Hastaların klinik muayenesiyle birlikte ameliyat öncesi ,ameliyat sonrası en son takipte basarak çekilmiş ayak grafileri alınmıştır.Bu grafilerde intermetatarsal açı (IMA),halluks abduktus açısı (HAV) ve tibial sesamoid pozisyonu (TSP) değerlendirildi.

Bulgular: Hastalarımızda IMA ve HAA'da sırasıyla $9.6^{\circ}$ ve $21.4^{\circ}$ ortalama düzelme sağlandı. IMA ve HAA'da ameliyat öncesi ve ameliyat sonrası radyografilerde istatiksel olarak anlamlı bir fark mevcuttu $(p<0.001)$.Kaynamama nedeniyle revize ettiğimiz bir hastamız hariç hiçbirisinde greft kullanmadık.Komplikasyon olarak 4 hastamızda kaynamama,2 hastamızda kaynamama,3 hastamızda intraoperative kılavuz teli kırılması,2 hastamızda vida kırılması,5 hastamızda yüzeysel enfeksiyon, 1 hastamızda FHL rüptürüyle karşılaştık.Takiplerde hiçbir hastamızda halluks valgus rekürrensiyle karşılaşmadık.

Sonuç: Biz Modifiye Lapidus artrodezi 1. sıra hipermobilitesiyle birlikte olan halluks valguslarda ve ciddi halluks valguslarda kullanabileceğimiz ve kuvvetli düzeltme sağlayabileceğimiz bir prosedür olduğu kanaatine vardık.

Anahtar kelimeler: halluks valgus; lapidus; hipermobilite; 1st tarsometatarsal artrodez

Corresponding Author*: Mehmet Orçun Akkurt, Ankara Yıldırım Beyazıt Üniversitesi, Yenimahalle Eğitim ve Araştırma Hastanesi, Ortopedi ve Travmatoloji Kliniği, Ankara/TURKEY

E-mail: mehorcun@gmail.com

ORCID: 0000-0003-4935-0143

Gönderim: 16.02.2020 kabul: 28.02.2020

Doi: $10.18663 / \mathrm{tjcl} .689886$ 


\begin{abstract}
Aim: In this study we presented a review of 67 Modified Lapidus procedure performed between 2004 and 2012.

Material and Methods: There were 61 females and 6 males. The mean age of patients was 51 years. The average follow-up was 10 years (6-14 years). The patients were evaluated preoperatively,postoperatively and last follow up using standard weight bearing radiographs and clinical examination.The radiographs were evaluated for intermetatarsal angle (IMA), hallux abductus angle (HAA) and tibial sesamoid position (TSP).
\end{abstract}

Results: The mean improvement at IMA and HAA was respectively $9.6^{\circ}$ and $21.4^{\circ}$.There was statically significant difference at IMA and HAA preoperatively and postoperatively $(p<0.001)$. We didn't use graft for any patients except one patient which was revised for nonunion.Complications include delayed union $(n=4)$, nonunion (2), intraoperative guide wire breakage $(n=3)$, screw breakage $(n=2)$, superficial infection $(n=5)$,FHL rupture $(n=1)$. There were no recurrences of hallux valgus at follow up.

Conclusion: Modified Lapidus procedure is both a predictable and durable procedure for the powerful correction for severe hallux valgus and first ray hypermobility.

Keywords: hallux valgus; lapidus; hypermobility; 1st tarsometatarsal arthrodesis

\section{Giriş}

Birinci tarsometatarsal eklem artrodezi ilk olarak 1991'de Albrecht tarafından tanımlanmısına karşın bu tekniğe ismini veren Lapidus tarafından 1934 yılında bu işleme 2. Metatars basis füzyonu eklenmiş hali bildirilmiştir [1,2]. Başlangıçta yetersiz fiksasyona bağlı başarısız sonuçlar mevcutken son 2-3 dekadda fiksasyon tekniklerinin geliştirilmesiyle başarılı sonuçlar bildirilmiş ve popülarite kazanmıştır.

Modifiye edilmiş tekniğinde 2. Metatars basisi artrodeze dahil edilmeyip sadece 1. Metatarso-küneiform artrodezi yapılır.Sıklıkla daha ciddi halluks valgusuyla birlikte 1 . Sıra hipermobilitesi olan hastalarda yapılmasına karşın 1. metatarso-küneiform artrozu olan hastalarda ve revizyon vakalarında da kullanılır ve buna ek olarak son yıllarda endikasyonları arasına medial kolon yetmezliği olan hastalarda eklenmiştir [3-5].

Modifiye Lapidus prosedürü, geçmişte ülkemizde dahil olmak üzere tüm dünyada kaynamama,yanlış kaynama ve kısalma gibi komplikasyonları nedeniyle sınırlı olarak tercih edilmekteydi $[9,10]$. Geçmişte yapılan çalışmalarda \% 12'ye varan oranlarda kaynamama oranları olmasına karşın yakın zamanda yeni nesil fiksasyon materyalleriyle birlikte ayak cerrahisi eğitimine olan ilginin artmasıyla birlikte cerrahi tekniğinde gelişmesiyle çok daha düşük oranlarda kaynamama oranları bildirilmiştir. Fiksasyon materyallerinin ve tekniğinin gelişmesinin bir diğer önemli avantajı da erken mobilizasyona izin vermesidir.

Çalışmamızda kaynamama ve kısalma gibi komplikasyonlardan kaçınmak için uyguladığımız teknikle yapılan modifiye Lapidus artrodezinin uzun dönem sonuçlarını retrospektif olarak değerlendirmeyi amaçladık.

\section{Gereç ve Yöntemler:}

Çalışmamızda 2004-2012 yılları arasında iki cerrah tarafından modifiye Lapidus artrodezi yapılan 106 hastadan takibi olan 79'unu retrospektif olarak değerlendirdik.Bu hastalardan orta ayak veya ard ayaktan ek cerrahi girişim geçirmiş olan 12 hastayı ameliyat sonrası sonuçları etkileyeceği için çıkardık ve kalan 67 hastayı çalışmamıza dahil ettik. Ek girişim uygulanan 44 hasta Tablo 1 de sunuldu. Tüm hastalara bilgilendirilmiş onam belgesi imzalatıldı ve çalışma için yerel etik kurul onayı alındı.

\begin{tabular}{|l|l|}
\hline \multicolumn{2}{|l|}{ Tablo 1. Hastalarımıza Yapılan Ek Girişimler } \\
\hline Ek Girişim & Sayı \\
\hline Akin Osteotomisi & $29(\% 29.8)$ \\
\hline Reverdin Osteotomisi & $7(\% 10.4)$ \\
\hline Küçük Parmak Artroplastisi & $8(\% 11.9)$ \\
\hline Weil Osteotomisi & $9(\% 13.4)$ \\
\hline
\end{tabular}

Hastaların 61'i kadın (\%91.04), 6'sı erkekti (\%8.96).Hastaların ortalama yaşı 51'di (40-66).37 hasta sağ ayaktan (\%55.28) 30 hasta ise sol ayaktan (\%44.72) opere edilmişti. Hastaların ek hastalıkları Tablo 2'de verilmiştir. Hastaların ortalama takip süresi yaklaşık 10 yıl'dı (6-14 yıl).

\begin{tabular}{l|l}
\hline Tablo 2. Hastalarımızın Ek Problemleri \\
\hline Ek Problemler & Sayı \\
\hline Sigara Kullanımı & $2(\% 2.98)$ \\
\hline Romatoid Artirt & $1(\% 1.49)$ \\
\hline Hipertansiyon & $23(\% 34.32)$ \\
\hline Diyabetes Mellitus & $4(\% 5.97)$ \\
\hline Kalp Hastalıkları & $12(\% 17.91)$ \\
\hline
\end{tabular}


Hastaların ameliyat öncesi, ameliyat sonrası en son takipte basarak çekilmiş ayak grafileri alınmıştı.Bu grafilerde intermetatarsal açı (IMA), halluks abduktus açısı (HAV) ve tibial sesamoid pozisyonu (TSP) değerlendirildi. Hastaların 1. sıra hipermobilitesi değerlendirilirken ayak bileği nötralde ve diğer metatarslar sabitken, 1. metatars dorsal ve plantar yönde hareket ettirilerek değerlendirildi. Ameliyat öncesi hastalara 1. Sıra transvers sıra hipermobilitesini değerlendirmek için bantlama grafisi çekildi (Şekil 1a ve 1b).

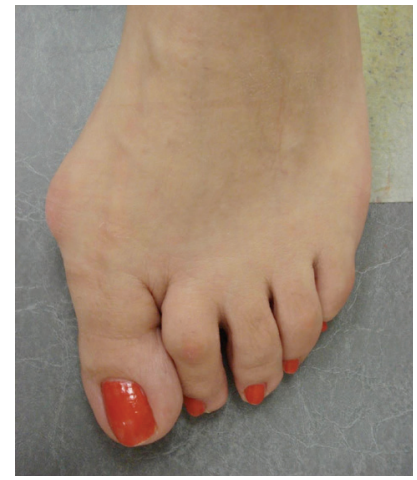

Şekil 1a. Bir Hastamızın Ayağının Bantlama Grafisi Öncesi Hali

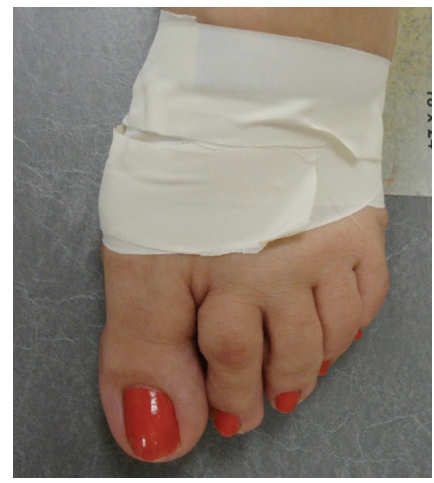

Şekil 1b. Bir Hastamızın Ayağının Bantlama Grafisi Için Hazırlanmış Hali

\section{Cerrahi Teknik}

Daha önce spinal cerrahi geçirmiş 3 hasta hariç tüm hastalar spinal anestezi altında, uyluk yada baldırdan turnike uygulanarak supin pozisyonda hazırlandı. Klasik olarak lateral gevşetme, bunyonektomi ve 1. Metatarso-küneiform artrodezi için 3 ayrı kesi yapıldı. İlk önce 1-2 web aralığından girilip lateral gevşetme yapıldı. Daha sonra medial insizyon yapılıp kapsül yazarlardan Öznur ve arkadaşlarının tariflediği Z-plasty tekniğiyle veya ters V şeklinde açıldı. Her zaman aşırı bunyenektomiden kaçınılıp minimal bunyenektomi yapıldı. Daha sonra dorsal insizyon yapılıp 1. Metatarso-küneiform ekleme ulaşıldı. Eklem açılırken mutlaka dişsiz lamina ayıracı kullanıdı. Eklem yüzleri hazırlanırken asla testere kullanılmadı. Küret ve ince osteotomlarla sadece kıkırdak temizliği yapılırken dorsaldeki kıkırdak en son alındı. Artrodez yapılmadan önce mutlaka hazırlanan eklem yüzeylerine çoklu delikler açıldı. 1. Metatars adduksiyon, supinasyon ve plantar fleksiyona getirilerek pozisyon verilip geçici olarak $\mathrm{K}$ telleriyle fikse edilip skopi kontrolü yapıldı. Fiksasyon için ilk vakalarda 2 veya 3 adet solid veya kanüle vida tercih edilirken (Şekil $2 a$ ve $2 b$ ), endüstrinin gelişmesiyle sonraki vakalarda başsız kompresyon vidaları ve uygun plaklar tercih edildi (Şekil 3a ve 3b).

35 hastamıza vida ile fiksasyon yapılrken 32 hastamıza dorsal anatomik plak ile fiksasyon yapıldı.

Ameliyat sonrası takipteilk 2 hafta ağırlıkvermeden mobilizasyona başlandı. 2. haftadan sonra alçı veya yürüme botuyla parsiyel yük

verilirken 4. haftada tam yüke geçildi.6 ve 10. haftalar arasında yakın radyografi kontrolü yapılarak alçı veya yürüme botu çıkarıldı. Bu süreçte yüzme ve sabit bisiklete izin verilirken 4 . aydan sonra diğer sporlara kontrollü şekilde başlandı.
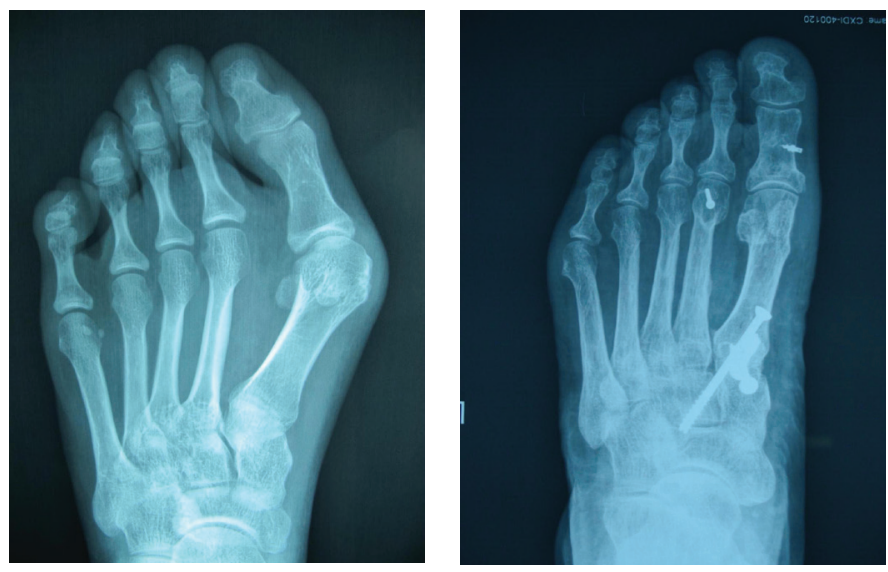

Şekil 2b. Hastamızın Sadece Vidayla Artrodez yapılmış ve ek Prosedür olarak Akin ve Weil Osteotomisi yapılmış Postoperatif Grafisi

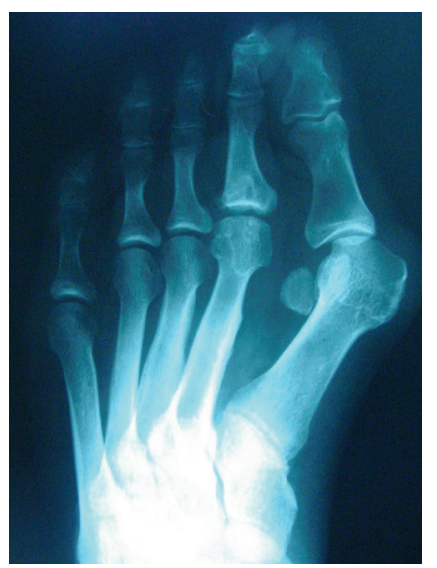

Şekil 3a. Bir Hastamızın Preopertatif Ayak Grafisi

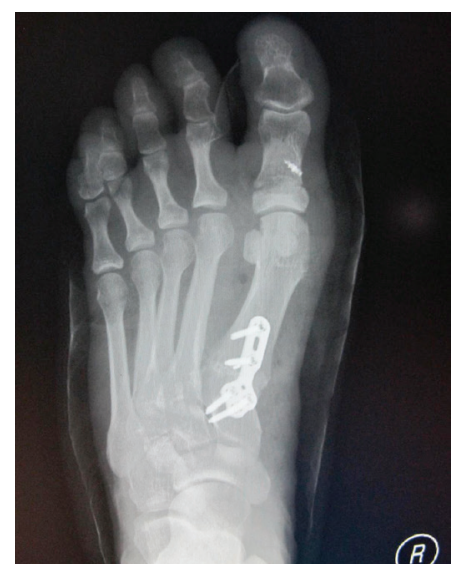

Şekil 3b. Hastamızın Plakla Lapidus Artrodezi ve Akin Osteotomisi yapılmış Postoperatif Grafisi

\section{Bulgular}

Hastaların ameliyat öncesi ve hemen sonrası ve son kontrollerinde çekilen radyografilerinde ölçülen IMA, HAA ve TSP değerleri Tablo 3'te verildi. IMA ve HAA karşılaştırmalarıyla elde edilen ortalama farklar Tablo 4'de verildi. IMA ve HAA'da ameliyat öncesi ve ameliyat sonrası radyografilerde istatiksel olarak anlamlı bir fark mevcuttu $(P<0.001)$.IMA'da ameliyattan hemen sonra çekilen ve son kontroldeki radyografilerinde istatiksel olarak anlamlı bir fark mevcut değildi. Buna karşın HAA'da ameliyattan hemen sonra çekilen ve son kontroldeki radyografilerde $1.2^{0}$ lik bir artış mevcuttu $(p<0.001)$. Bunu 
kısmen deformitenin tekrarlamasına, kısmen de ameliyattan hemen sonra çekilen grafilerin yük vermeden çekilmiş olmasına bağladık. Son kontrolde yük verilerek çekilen radyogafilerde sesamoid pozisyonu ameliyat öncesine göre karşılaştırıldığında çok daha uygun pozisyondaydı.

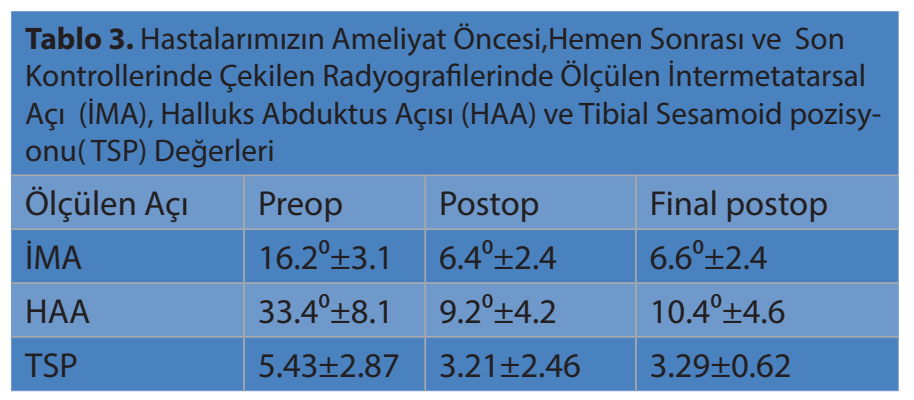

\begin{tabular}{|c|c|c|}
\hline $\begin{array}{l}\text { Ölçümlerin } \\
\text { Karşılaştırılması }\end{array}$ & $\begin{array}{l}\text { Ameliyat önc- } \\
\text { esi ve ameliyat } \\
\text { sonrası radyolojik } \\
\text { ölçümler arası } \\
\text { ortalama fark }\end{array}$ & $\begin{array}{l}\text { Ameliyat sonrası } \\
\text { ve son kontrolde } \\
\text { yapılan radyolo- } \\
\text { jik ölçümler arası } \\
\text { ortalama fark }\end{array}$ \\
\hline IMA & $9.6(p<0.001)$ & $-0.2(p=0.06)$ \\
\hline HAV & $21.4(p<0.001)$ & $-1.2(p=0.001)$ \\
\hline
\end{tabular}

Hastalarımızın 61'inde (\% 91.04) ortalama $70 \pm 24.4$ günde kaynama sorunsuz olarak gerçekleşmişti. Gecikmiş kaynama olarak kabul ettiğimiz 4 hastamızda (\%5.97) herhangi bir müdaheleye gerek kalmadan zaman içinde kaynama gerçekleşti. Kaynamama olarak kabul ettiğimiz 2 hastanın (\% 2.98) biri asemptomatik olduğu için herhangi bir müdahele yapılmadı. Semptomatik olan diğer hastamıza iliak kanattan otojen greft alınarak revizyon artrodez yapıldı. Kaynamama görülen 2 hastamızda sigara kullanmıyordu.

Hastalarımızda gelişen komplikasyonlar Tablo 5'de verildi.

\begin{tabular}{l|l}
\hline \multicolumn{2}{l}{ Tablo 5. Hastalarımızda gelişen komplikasyonlar } \\
\hline Komplikasyonlar & Sayı \\
\hline Gecikmiş Kaynama & $4(\% 5.97)$ \\
\hline Kaynamama & $2(\% 2.98)$ \\
\hline $\begin{array}{l}\text { Intraoperatif Kılavuz Teli } \\
\text { Kırılması }\end{array}$ & $3(\% 4.47)$ \\
\hline Vida Kırılması & $2(\% 2.98)$ \\
\hline Yüzeysel Enfeksiyon & $5(\% 7.46)$ \\
\hline FHL Rüptürü & $1(\% 1.49)$ \\
\hline
\end{tabular}

İntraoperatif kılavuz teli ve vidası kırılan toplam 5 hastamıza (\% 7.46) çıkarmak için girişimde bulunmadık. Hastalarımızın takiplerinde bunlarla ilgili herhangi bir şikayete rastlamadık. Yüzeysel enfeksiyon gelişen 5 hastamız (\% 7.46) yakın takip ve oral antibiyotik tedavisiyle düzeldi. $\mathrm{FHL}$ rüptürü gelişen 1 hastamıza (\% 1.49) distal interphalangeal ekleme artrodez önerildi ancak hasta kabul etmedi.

\section{Tartışma}

Lapidus prosedürü olarak bilinen bu teknikte 1934 yılında tanımlandığından itibaren etkinliğini arttırmaya yönelik pek çok modifikasyon yapılmıştır [2]. Literatürde eklem hazırlığı, fiksasyon tipi, greft kullanımı, yük verme süresinin uzunluğu gibi pek çok parametrede değişiklikler yapılarak değişik oranlarda başarı bildirilmiştir. Modifiye lapidus prosedüründe bildirilen başarı oranları \% 75 ila \% 96 arasında değişmektedir [11]. Bu yüksek başarı oranlarına karşın bazı serilerde bildirilen yüksek kaynamama oranları ve bunların neredeyse yarısının semptomatik olması hala en önemli problem olarak bildirilmektedir. Sangeorzan ve Hansen geçmişte \% 10 gibi yüksek bir oranda kaynamama bildirmiştir [7]. Patel ve arkadaşları 227 hastalık geniş serilerinde \% 5.7 oranında kaynamama bildirmiştir [12]. Biz hastalarımızda eklem küretaj tekniğini kullanarak eklemi artrodez için hazırladık. Bu tekniğin kısalmaya yol açmaması, artrodez hattında uyumu iyi sağlaması gibi avantajları mevcutttur. Ancak bazı otörler bu teknikle subkondral plak üstünde kalsifiye kıkırdağın artık bir tabakası kalabileceğini ve bu tabakanın kaynamaya engel olabilecek doğal bir bariyer olabileceğini bildirmişlerdir [13]. Bizim serimizde eklem küretaj tekniğiyle kaynamama oranı otojen greft veya allogreft kullanmamıza rağmen \% 2.98'di ve biz bu düşük kaynama oranını iddia edilenin aksine eklem hazırlanırken motorize alet kullanılmaması, eklem yüzeylerinin dikkatli bir şekilde hazırlanması ve uygun hasta seçimine bağladık.

Sangeorzan ve Hansen Modifiye Lapidus prosedürü uyguladıkları 32 hastanın 40 ayağını retrospektif olarak değerlendirmişler ve IMA ve HAA'da sırasıyla $8^{\circ}$ ve $15^{\circ}$ ortalama düzelme sağladıklarını bildirmişlerdir [7]. Myerson ve arkadaşları benzer şekilde Modifiye Lapidus prosedürü uyguladıkları 67 hastayı değerlendirmişler ve iMA ve HAA'da sırasıyla $8.5^{\circ}$ ve $21.5^{\circ}$ ortalama düzelme sağladıklarını bildirmişlerdir[14]. Myerson ve arkadaşları ayrıca TSP'de olan düzelmeyi de belirtmişlerdir. Bizim de Modifiye Lapidus prosedürü uyguladığmız hastalarda elde ettiğimiz sonuçlar yukarda belirtilen çalışmalarda ki sonuçlarla karşılaştırılabilir şekildeydi ve IMA ve HAA'da sırasıyla $9.6^{\circ}$ ve $21.4^{\circ}$ ortalama düzelme sağladık.

Son zamanlarda Modifiye Lapidus prosedüyle ilgili tartışılan bir başka önemli konu ise artrodez için kullanılan fiksasyon tekniğidir. Güncel çalışmaların bazılarında kompresyon vidasıyla birlikte kilitli plak kullanımı tavsiye edilmiş ve bu tekniğin çapraz 2 vidadan daha stabil olduğu bildirilmiştir [15]. Fakat bu tezi destekleyen herhangi bir prospektif, randomize çalışmaya rastlayamadık. Biz de çalışmamızda her 
2 tekniği de uygulamamıza karşın hasta sonuçları arasında bir fark saptayamadık.

Lapidus prosedüründen sonra klasik yaklaşım kaynama görülen kadar alçıda tutup klinik ve radyografik olarak kaynama sağlanınca alçı çıkarılıp yüklenmeye izin verilmesidir. İmmobilizasyon süresi ve yük vermeyle ilgili standart bir prosedür tanımlanmamasına karşın erken yük vermeyle ilgili başarılı sonuçlar bildirilmiş ve bu fikirler geçmişte de varmış $[16,17]$. Lapidus tekniği ilk tanımladığında fiksasyonu kat küt sütürlerle yapmasına karşın hastaların özel bir ayakkabıyla yürümesine izin verilmiş [2]. Erken yüklenmeyle alçı içinde gelişmesi muhtemel osteopeni, kas atrofisi ve derin ven trombozu gibi komplikasyonların önüne geçilmiş olur. Ancak her ne kadar stabil bir fiksasyon yapsak da erken yüklenmeyle füzyon sahasında gelişebilecek mikrohareketlere bağlı makaslama kuvvetleri kaynamayı etkileyebilir. Biz de kendi hastalarımızda yüklenmeye 2 . haftadan sonra parsiyel olarak başladık ancak alçı içinde gelişmesi muhtemel komplikasyonların önüne geçmek için mobilizasyona hemen başladık. 4. haftadan itibaren tam yüklenmeye geçtik ve bu protoklle ilgili bir problemle karşılaşmadık.

Çalışmamızın bazı kısıtlamaları mevcuttu. Birincisi, retrospektif olan bu çalışmamızın greftlemeyle veya yeni nesil özel kılavuzlarla yapılmış olan Lapidus prosedürleri gibi herhangi bir kontrol grubu yoktu. Bir diğer kısıtlama takiplerde posoperatif hemen grafiyle karşılaştırıldığında görülen redüksiyon kaybıydı. Biz bunu grafilerin yük veirlmeden çekilmesine bağladık ancak bu grafileri erken dönemde yük vererek tekrarlayabilirdik. Bunlara ek olarak çalışmamızın retrospektif olması nedeniyle sonuçlarda ön yargılı davranma riski mevcuttu.

\section{Sonuç}

Biz çalışmamızda greft kullanmadan, uygun eklem hazırlığıyla her 2 fiksasyon tekniğiyle yüksek oranda kaynama elde ettik ve biz Modidfiye Lapidus prosedürünün 1. sıra hipermobilitesiyle birlikte olan halluks valguslarda ve ciddi halluks valguslarda kullanabileceğimiz ve kuvvetli düzeltme sağlayabileceğimiz bir teknik olduğu kanaatine vardık.

\section{Maddi destek ve çıkar ilişkisi}

Bu çalışma Türkiye Çocuk Endokrinoloji ve Diyabet Derneği tarafından maddi olarak desteklenmiştir. Yazarın herhangi bir çıkar dayalı ilişkisi yoktur.

\section{Kaynaklar}

1. Albrecht $\mathrm{GH}$ : The pathology and treatment of hallux valgus. Russ Vrach 10:14, 1911

2. Lapidus PW. The operative correction of the metatarsus primus varus in hallux valgus. Surg Gynecol Obstet 1934; 58: 183-91
3. Clark HR, Veith RG, Hansen ST Jr. Adolescent bunions treated by the modified Lapidus Procedure. Bull Hosp Joint Dis Ortho Inst 1987; 47: 109-22.

4. Bednarz PA, Manoli A II. Modified Lapidus procedure for the treatment of hypermobile hallux valgus. Foot Ankle Int 2000; 21: 816-21.

5. Faber FW, Mulder PG, Verhaar JA. Role of first ray hypermobility in the outcome of the Hohman and the Lapidus procedure: a prospective, randomized trial involving one hundred and one feet. J Bone Joint Surg 2004; 86: 486-95.

6. Bacardi BE, Boysen TJ. Considerations for the lapidus operation. J Foot Surg 25:133-138,

7. Sangeorzan BJ, Hansen ST. Modified Lapidus procedure for hallux valgus. Foot Ankle 1986; 9: 262-66.

8. Saffo G, Wooster MF, Stevens M, Desnoyers R, Catanzariti AR. First metatarsocuneiform joint arthrodesis: a five-year retrospective analysis. J Foot Surg 1989; 28: 459-65.

9. Mclnnes BD, Bouché RT. Critical evaluation of the modified Lapidus procedure. J Foot Ankle Surg 2001; 40: 71-90.

10. Thompson IM, Bohay DR, Anderson JG. Fusion rate of first tarsometatarsal arthrodesis in the modified Lapidus procedure and flatfoot reconstruction. Foot Ankle Int 2005; 26: 698-703.

11. Kopp FJ, Patel MM, Levine DS, Deland JT. The modified Lapidus procedure for hallux valgus: a clinical and radiographic analysis. Foot Ankle Int 2005; 26: 913-17.

12. Patel S, Ford LA, Etcheverry J, Rush SM, Hamilton GA. Modified lapidus arthrodesis: rate of nonunion in 227 cases. J Foot Ankle Surg 2004; 43: 37-42.

13. Johnson JT, Schuberth JM, Thornton SD, Christensen JC. Joint curettage arthrodesis technique in the foot: a histological analysis.J Foot Ankle Surg 2009; 48: 558-64.

14. Myerson M, Allon S, McGarvey W. Metatarsocuneiform arthrodesis for management of hallux valgus and metatarsus primus varus. Foot Ankle 1992; 13: 107-15.

15. Klos K,Gueroguiev B,Muckley T,Fröber R,Hofmann GO,Schwieger G,Windolf M. Stability of medial locking plate and compression screw versus two crossed screws for lapidus arthrodesis. Foot Ankle Int 2010; 31: 158-63

16. King CM, Richey J,Patel S,Collman DR. Modified lapidus arthrodesis with crossed screw fixation: early weightbearing in 136 patients. J Foot Ankle Surg 2015; 54: 69-75.

17. Blitz NM, Lee T, Williams K, Barkan H, DiDimenico LA. Early weight bearing after modified lapidus arthodesis: a multicenter review of 80 cases. J Foot Ankle Surg 2010; 49: 357-62. 